\title{
Research on the Application of Big Data in the Construction of Agricultural E- commerce Supply-side Platform
}

\author{
Yan $X u^{1, a}$ \\ ${ }^{1}$ Yango University, Fuzhou City, Fujian Province, 350015, China \\ a many0902@163.com
}

Keywords: Big Data; Agricultural E-commerce; Supply Side; Platform Construction

\begin{abstract}
Agricultural big data refers to the application of big data concepts, technologies and methods in agriculture. It involves agricultural production, operation, management and service. It is cross-industry and multi-discipline data analysis and mining. Agricultural big data can guide China's agricultural production, circulation and agricultural service consumption. Based on the author's learning and practical experience, this paper first analyzed the significance of big data to the construction of agricultural e-commerce supply-side platform, and then discussed the application ways of big data in the construction of agricultural e-commerce supply-side platform.
\end{abstract}

\section{Introduction}

The optimization of the supply-side structure of the agricultural economy is to optimize the allocation of various agricultural resources from the supply side to ensure the balance between consumption demand and supply based on market demand. In the context of the booming big data technology, big data has been used into all walks of life and becomes more closely linked to agriculture. With the release of Action Plan for Promoting Big Data Development and other guidance documents, big data, cloud computing and other new technologies have gradually become important tools for developing agricultural economy, cultivating new farmers and constructing beautiful villages. The combination of agricultural economy and big data, Internet of Things and other technologies will better integrate the data of agricultural production, processing, circulation and other links. This will help data play its role in decision-making guidance and promote the integration of agriculture and more industries to create an agricultural economic chain with the integration of production and marketing, information sharing, high quality and efficiency.

\section{The Significance of Big Data to the Construction of Agricultural E-commerce Supply-side Platform}

\subsection{To reduce the circulation cost of agricultural production}

Agricultural production in most parts of China is dominated by peripheral sales. Blind production and narrow sales channels result in high production and operation costs. In the era of information connectivity, only by mastering the market information in a timely manner, taking market demand as the guidance, and engaging in agricultural production in a planned and step-bystep manner, can the production and circulation costs be effectively reduced. The application of big data technology can break the limitations of time and space, capture the latest information in the market in time and realize the information connectivity in all aspects of agricultural production, so as to effectively link various agriculture-related resources and avoid losses caused by information asymmetry. At the same time, a platform for agricultural e-commerce can be established, which is used to release information of agricultural products, such as information about sales, exhibition and transaction. The two parties can quickly connect with each other on the mobile networks, and integrate information with big data technology. This will help optimize resource allocation according to changes in consumer demand. In turn, the circulation costs of each link are reduced. 


\subsection{To improve the efficiency of agricultural modernization}

China has problems of decentralized management, high land rent and abuse of pesticides and fertilizers in agricultural production. China now vigorously advocates to establish a modern agricultural system. In order to effectively promote the optimization of the agricultural economic supply-side structure, realize large-scaled, modern and innovative agricultural operation, and innovate the agricultural service system, related departments must rely on advanced technology to make up for the weakness. The application of big data technology can help agricultural producers to acquire more innovative agricultural production methods, which not only improves the overall quality of agricultural producers, but also is a necessary way to cultivate new agricultural production subjects. At the same time, relying on big data technology to integrate various agriculture-related data, we can master the land information in different regions to realize the rational distribution of land resources, set up a scientific land transfer system, rationally use idle land and reduce land rental costs.

\subsection{To promote the transformation and upgrading of the agricultural economy}

The agricultural production in different regions of China is quite different. The consumption habits vary widely and the needs of users are diverse. To integrate these information and better master the market conditions to optimize the allocation of agricultural resources and maximize the benefits of agricultural supply needs big data technology support. The combination of big data technology and agricultural economy has promoted the large-scale and standardized agricultural production. Especially the rapid transmission of information based on the Internet helps to cultivate new agricultural management entities, such as agricultural enterprises and planting experts. These new types of entities are different from the small-scale peasant economy. They need to grasp information about the market input and output, and market supply and demand in a timely manner. They need to build new industrial systems with big data and new technologies, and use the ecommerce platform to achieve rapid product circulation. It can be said that big data technology is the driving force behind the optimization of agricultural supply-side structure. The big data-based agricultural product traceability system integrates big data, radio frequency identification and cloud platform, so that the information of production and marketing of agricultural products can be traced. The information sharing between the upstream and downstream of the industrial chain can be strengthened, and the agricultural economic service system can be further optimized.

\section{Application Ways of Big Data in the Construction of Agricultural E-commerce Supply-side Platform}

\subsection{Big data collection}

Related departments need to establish and improve the agricultural big data collection system, and clarify the responsibility for information collection. They need to widely use large-scale data collection technologies, such as distributed high speed, high-reliability data crawling and highspeed data full image to widely collect Internet data. Agricultural-related data monitoring and statistical system should be further optimized. They need to improve statistical indicators, expand the scope of collection and monitoring, improve the means and methods of data collecting and monitoring, and explore the statistical monitoring from the sample survey to the full-sample and full-data pilot. The data collection function of the station in the village and related data collection and sharing functions should be improved.

\subsection{Big data analysis}

Related departments can construct national and provincial agricultural big data exchange centers. Relying on cloud computing technology and with the integration of basic hardware and software resources and structural reconstruction, they can achieve unified management of resources, ondemand distribution and comprehensive utilization. A large-scale agricultural product big data sharing platform that links upstream and downstream can realizes data connectivity, open access, 
and quick visit.

\subsection{Big data application}

Related departments can gradually carry out agricultural intelligent actions and take advantage of big data technology to improve the level of agricultural production, operation, management and service. They can cultivate a group of digital, smart, lean and modern ecological agriculture models, accelerate the improvement of new agricultural production management system, cultivate a diversified agricultural Internet management service model, and gradually establish a traceability system for quality and safety of agricultural and sideline products and agricultural materials. They can regularly issue monitoring and forecasting warnings to avoid frequent occurrence of the event that low-quality agricultural products are not dealt with well.

\subsection{Big data operation}

The construction of big data service system should be improved. Relying on leading enterprises, cooperative economic organizations, standardized production bases, agricultural science and technology demonstration parks, large-scale breeding households and agricultural products websites, related departments can provide one-stop service for the supply and marketing of agricultural products. They can strengthen the construction of information service system for farmer professional cooperative organizations and large-scale breeding households to form a multimode information dissemination system that combines TV, telephone and network. Moreover, communication and cooperation with China Unicom, China Mobile, China Telecom, radio and television can be strengthened to integrate various types of agricultural service platform resources in different places and with multiple service numbers and support from different expert teams. Then a 12316 information service system for farmers, agriculture and rural areas that covers the whole province and integrates telephone hotline, mobile phone text messages, agriculture-related website, radio and television, and APP technology can be established.

\subsection{Big data management}

It is necessary to establish and improve the platform management system for national and provincial agricultural big data exchange centers, including application access, application unloading, sandbox development, security incidents and violations. In addition, a platform operation system can be established and related departments should manage agricultural information hierarchically according to the position, service object and service content and in accordance with national information security laws and regulations. Besides, a platform security and confidentiality system should be established and improved.

\subsection{Big data standard}

Focusing on basic data, data processing, data security, data quality, data products, platform standards, data application and data services, related departments can establish a standard system, and promote the development and application of relevant standards in the fields of metadata, databases, data modeling, data exchange and management.

\subsection{Big data demonstration}

Related departments can launch pilot demonstrations around precision agriculture, application of Internet of Things, product quality and safety traceability and online marketing of agricultural products, and actively explore new ways and methods of the application of big data technology in agriculture, high-standard production of agricultural products, high-quality brand development and online sales of products.

\subsection{To cultivate new-type agricultural talents}

One of the important tasks of the optimization of agricultural economic supply-side structure is to cultivate new agricultural subjects with overall quality who have big data thinking, are familiar with the business operation model under the network economy and master the latest agricultural 
knowledge. Related departments can combine big data and other technologies with agricultural technology education, establish an online agricultural science and education service platform and set up educational courses for objects with different levels to help the majority of agricultural business entities master new technologies and know e-commerce operation well. They can provide farmers with online technical guidance to lead them to learn new knowledge independently and become compound agricultural technology talents in the new era. Local governments can cooperate with local agricultural enterprises and technical colleges to integrate distance learning and physical education together. They can also invite professionals to teach new knowledge to farmers, so that they can truly become the driving force for modern agriculture. For example, the Ministry of Agriculture and Rural Affairs established a science and education cloud platform for national users by means of big data, cloud computing and other advanced technologies. This establishes a communication bridge between agricultural technology experts and farmers, and integrates rich educational resources to facilitate farmers to learn new knowledge and master market dynamics at any time and anywhere with the mobile networks. This is an effective means of cultivating new professional farmers.

\subsection{To establishing an agricultural big data sharing platform}

The importance of data application in the era of big data is self-evident, and mastering core data is the key to improving competitiveness. Government departments attach great importance to the application of big data, especially the agriculture-related departments. They advocate to share big data and require local governments to establish data sharing platforms as soon as possible to eliminate agricultural data information isolated islands and optimize data resources. However, due to the large number of agricultural institutions, the supervision of relevant data belongs to different systems. Most information is used internally by the department. Information exchange between different institutions is ineffective, which leads to data redundancy and information isolated islands. This results in huge waste of technology and human resources. In order to improve the utilization rate of agriculture-related data and provide a basis for scientific decision-making of agricultural economic development, it is necessary to do a top-level design work on agriculture-related data. It is necessary to formulate agricultural resource management standards at the national level, promote information sharing among different institutions, clarify the rights and responsibilities of different institutions and departments and build a big data sharing platform for multidirectional circulation of information to improve the credibility of the use of agricultural data, and reduce resource maintenance costs. In addition, all levels of departments are required to do a good job of information integration and public data connection and convergence. They should make the agriculture-related data shared by the whole people, protect the public's right to know and make suggestions and give full play to the value of agricultural data with an open attitude.

\section{Summary}

In the transformation period of New Normal in China's economic development, the integration of big data and agricultural e-commerce supply side has become a force that can not be ignored to promote the optimization of agricultural economic supply-side structure. We must grasp this development opportunity, implement supply-side reform with agricultural big data application, foster new agricultural entities and achieve rapid development of agricultural economy with new growth drivers to benefit farmers with advanced technology.

\section{Acknowledgement}

Project Fund: Construction of Supply-side Platform for Agricultural Ecommerce in Fujian Province under the Background of Big Data(Middle and Young people Project of Education Department of Fujian Province, JAS180775)

\section{References}


[1] Li Fang, Wang Luyao and Guo Yuanyuan. An Analysis of the Role of Agricultural Big Data in Agricultural Economic Management [J]. Modern Marketing (Late issue), 2018, (02): 8-9.

[2] Wang Hengjin. A Discussion On the Reform of Internet Agriculture and Agricultural SupplySide Structure [J]. Modern Economic Information, 2016, (19): 315.

[3] Li Mingshui. Building a Smart Agriculture Center in Nanjing to Promote the Development of Urban Modern Agriculture [J]. Agricultural Engineering Technology, 2016, 36(15): 22-24.

[4] Editors of this journal. The Great Significance OF Big Data to the Development of Modern Agriculture in China [J]. Agricultural Engineering Technology, 2016, 36(09): 62-63.

[5] Zhou Ling, Wang Mingyu. A Research on the Status and Trend of Agricultural E-commerce Development under the Background of "Internet +" [J]. China Business and Tread, 2015, (13): 4850. 